Int. J. Dev. Biol. 54: 105-111 (2010)

doi: $10.1387 / \mathrm{ijdb} .082836 \mathrm{tk}$

\title{
In vitro germ cell differentiation during sex differentiation in a teleost fish
}

\author{
TOHRU KOBAYASHI $*, 1,2,3$ \\ ${ }^{1}$ Laboratory of Molecular Developmental Biology, Graduate School of Nutritional and Environmental \\ Sciences, University of Shizuoka, Japan, ${ }^{2}$ The United Graduate School of Agricultural Science, Ehime \\ University, Matsuyama, Japan and ${ }^{3}$ Division of Reproductive Biology, National Research Institute of \\ Aquaculture, Tamaki, Japan.
}

\begin{abstract}
To clarify the sexually dimorphic mechanisms of gonadal sex differentiation, we established an in vitro culture system for gonadal sex differentiation using the teleost fish Oreochromis niloticus. In vivo, the entry of germ cells into meiosis occurs around 35 days after hatching (dah) in XX gonads, whereas in XY gonads, meiotic cells became differentiated around 85 dah. In our in vitro culture system using gonads from young fry at 23 dah, the meiotic cells in the XX gonads appeared after 21 days of culture. In contrast, in the XY gonads, no meiotic cells were detected after 21 days. These results indicate that germ cell differentiation in this culture system progresses in a manner similar to that in vivo. To identify the gene products that are involved in the entry of germ cells into meiosis or in the arrest of germ cells at the gonial stage of gonadal sex differentiation, we performed subtractive hybridization screening with this in vitro culture system. From the screening process, we identified the female-related gene, $F R-3$, which is a homolog of zebrafish nanos-related gene (nos). The nos gene was expressed after gonadal formation around 35 dah in $\mathrm{XX}$ gonads, but not in $\mathrm{XY}$ gonads. In situ hybridization indicated that nos is expressed in oogenic meiotic cells, but not in spermatogenic meiotic cells. Further examination revealed that nos was expressed in oogenic meiotic cells after gonadal formation, specifically in teleost fish. Together, nos may be also involved in oogenic meiosis, with the exception of primordial germ cell migration.
\end{abstract}

KEY WORDS: germ cell, meiosis, sex differentiation, teleost, in vitro

\section{Introduction}

Gametogenesis consists of the following four events: 1) stem cell renewal; 2) proliferation; 3) meiosis; and 4) final maturation. In general, female gametogenesis in the form of oogenesis proceeds faster than male gametogenesis in the form of spermatogenesis. In particular, meiosis is the most important event in gametogenesis. Although many researchers have tried to clarify the mechanisms of meiosis, the details remain unclear. In meiosis, there are two crucial phenomena: the entry of embryonic germ cells into meiosis during gonadal sex differentiation (sex differentiation of germ cells and oogenesis), and the entry of spermatogenic cells into meiosis, i.e., the development of spermatocytes (spermatogenesis). For mammals, previous reports have suggested the possibility that meiosis-inducing and meiosis-preventing substances are present during gonadal sex differentiation (McLaren, 2003). Recent reports have indicated that in mice, loss of retinoic acid signaling plays an important role in the entry of embryonic germ cells into meiosis via CYP26B1 (Bowles et al., 2006; Koubova et al., 2006). However, it remains unclear whether this represents a conservative cascade for germ cell differentiation in non-mammalian vertebrates.

In lower vertebrates, especially teleost fish, many studies have been conducted on gonadal sex differentiation (Nakamura et al., 1998). Recent studies implicate $D M Y$ (a DMRT1 homolog) as a male-determining gene in the teleost fish medaka, Oryzias latipes (Matsuda et al., 2002; Nanda et al., 2002), although DMY is present only in two species of the genus Oryzias (Matsuda et al., 2003). Nevertheless, the mechanisms of gonadal sex differ-

\footnotetext{
Abbreviations used in this paper: dah, days after hatching; DMC, dosage suppressor of mck1 homolog; FR, female-related gene; nos, nanos-related gene.
}

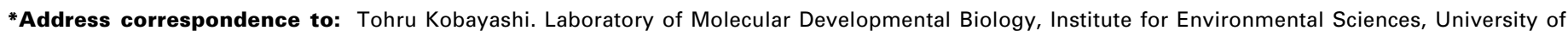
Shizuoka, 52-1 Yada, Shizuoka 422-8526, Japan. e-mail: tohruk@u-shizuoka-ken.ac.jp
} 
entiation, which include sexual dimorphisms of germ and somatic cells, are not yet understood. In vertebrates, one of the conservative phenomena for gonadal sex differentiation is the entry of embryonic germ cells into meiosis during gonadal sex differentiation in females (McLaren and Southee, 1997). In some species of lower vertebrates, before entry of the embryonic germ cells into meiosis, germ cell proliferation occurs in the female gonads, whereas no proliferation is observed in the male gonads (Hardisty, 1967). However, to date, no information has emerged on the mechanisms underlying the entry of embryonic germ cells into meiosis during gonadal sex differentiation, especially in lower vertebrates, mainly due to a lack of information regarding the molecular events and adequate functional analysis, such as an in vitrosystem for analyzing meiosis during gonadal sex differentiation. To clarify the mechanisms of meiosis, tools that specifically recognize the meiotic stage are required. Dmc1 and Scp3 are specific gene products that are expressed in the leptotene to pachytene meiotic prophase (Wolgemuth, 2003). In yeast, the absence of Dmc1 prevents interhomolog interactions, which illustrates the role of Dmc1 in promoting interhomolog recombination during meiosis (Schwacha and Kleckner, 1997). Furthermore, the Dmc1-null mutation in mice causes meiotic arrest at the zygotene stage without homolog synapsis (Pittman et al., 1998) or with occasional synapsis between non-homologs (Yoshida et al., 1998). The role of Dmc1 in promoting interactions between homologous chromosomes appears to be conserved from yeast to mammals (Tarsounas et al., 1999). On the other hand, our recent study indicates that the Dmc1 protein is expressed in meiotic prophase specifically during spermatogenesis in the teleost fish Anguilla japonica (Kajiura-Kobayashi et al., 2005).

The teleost fish Nile tilapia Oreochromis niloticus is one of most intensely studied species with respect to gonadal sex differentiation (Nakamura et al., 1998; Kobayashi et al., 2000. $2002,2003,2008)$, although a sex-determining gene has not yet been identified. In tilapia, germ cell proliferation occurs and the cells enter into meiosis in genetic females, whereas in genetic males, the germ cells never enter into meiosis during gonadal sex differentiation. To clarify the mechanisms of sexual dimorphism of germ cell differentiation during gonadal sex differentiation, an in vitro culture system that enables functional analysis is required. Therefore, we attempted to establish an in vitro culture system for germ cell differentiation during gonadal sex differentiation in tilapia, with emphasis on the entry of germ cells into meiosis. In our in vitro system, germ cell differentiation and meiosis during gonadal sex differentiation progress in a manner similar to that observed in vivo. To identify the gene products that are involved in the entry of germ cells into meiosis or in germ cell arrest at the gonial stage of gonadal sex differentiation, we performed subtractive hybridization screening using this in vitro culture system.

\section{Results}

\section{Germ cell differentiation in vivo}

In tilapia, the gonadal primordium is formed at 3 dah. The first sexual dimorphism appears after 9 dah as a difference in germ cell numbers between the sexes, and
TABLE 1

\section{EFFECTS OF 17A-METHYLTESTOSTERONE ON SEX DIFFERENTIATION IN TILAPIA*}

\begin{tabular}{lcc} 
& Male $^{* *}$ & Female $^{\star *}$ \\
\hline XX control & $0 / 40$ & $40 / 40$ \\
XX MT-treatment & $45 / 45$ & $0 / 45$ \\
\hline
\end{tabular}

${ }^{*} \mathrm{XX}$ fry were treated with $17 \mathrm{a}$-methytestosterone (MT) from 12 to 20 dah

** Phenotypic sex examined at 50 dah.

the second sexual dimorphism appears at 20-25 dah as a difference in histogenesis between the sexes, e.g., the formation of the anlagen of the intratesticular efferent duct and ovarian cavity in $X Y$ and $X X$ fry, respectively. Meiotic cells first appear after 35 dah in $X X$ fry, but not in $X Y$ fry. In $X Y$ fry, the initiation of spermatogenesis is seen after 50 dah, and the first meiotic cells are observed around 85 dah. Our findings for the histogenesis are in agreement with those reported previously (Kobayashi et al., 2000; 2003; 2008) and are summarized in Fig. 1.

\section{Specific expression of Dmc1 in meiotic germ cells}

The cloning of the tilapia Dmc1 and Rad51 cDNAs and their phylogenetic analysis have been published elsewhere (KajiuraKobayashi et al., 2005). In this study, we examined the localization of Dmc1 protein in the gonads using the anti-Dmc1 antibody. Immunoblot analysis for the Dmc1 protein was performed using testis preparations and recombinant tilapia Dmc1 and Rad51 protein derived from the rabbit reticulocyte lysate system. Dmc1 appeared as a $37-\mathrm{kDa}$ band in the testicular protein preparation. When the anti-Dmc1 antibody was used in blots with recombinant Dmc1 and Rad51, only the recombinant Dmc1 protein was immunostained (Fig. 2A), which suggests that this antibody specifically recognizes tilapia Dmc1. Immunohistochemical examination of Dmc1 showed that in the testis. Dmc1 was localized

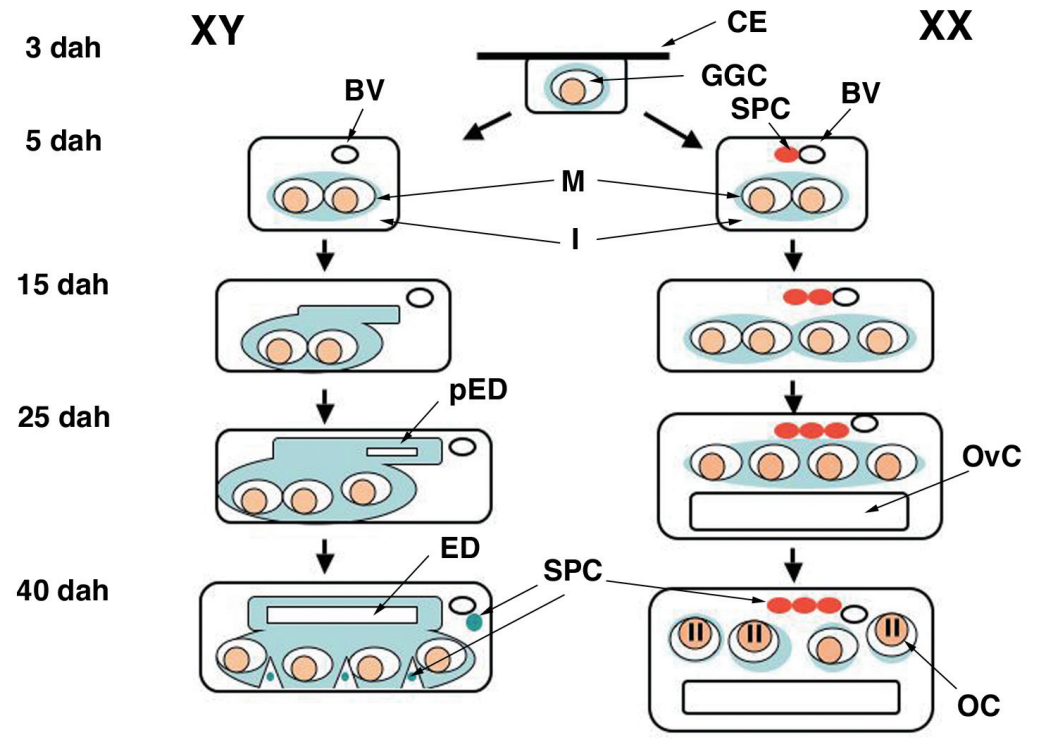

Fig. 1. Sexual dimorphism during gonadal differentiation in tilapia. Schematic representation of gonadal histogenesis during gonadal differentiation. CE, coelomic epithelium. GGC, gonial germ cell. SPC, steroid producing cell. BV, blood vessel. OvC, ovarian cavity. $p E D$, anlagen of intratesticular efferent duct. Oc, oocyte. ED, intratesticular efferent duct. $M$, medullary cell. I, interstitum. Dah, days after hatching. 
A

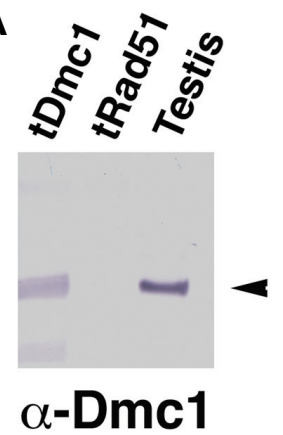

Fig. 2 (Left). Specificity of antiDmc1 antibody and localization of Dmc1 protein. (A) Specificity of anti-Dmc1 antibody. Anti-Dmc1 antibody recognized recombinant Dmc1 protein, but not recombinant Rad51 protein. Anti-Dmc1 antibody recognized 37-kDa band in the testicular protein preparation. (B) Dmc1 was localized in spermatocytes, but not in spermatogonia, spermatids or sperma-
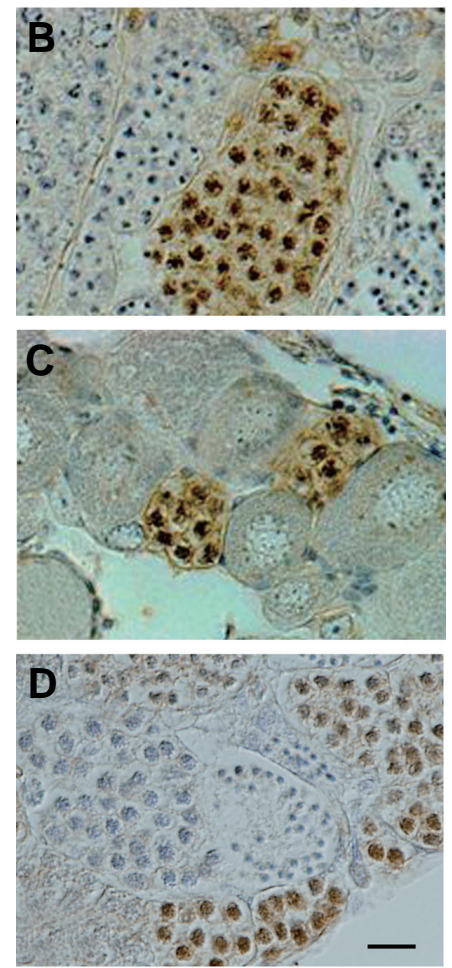

tozoa. Further examination revealed that Dmc1 was localized in early primary spermatocytes but not in the late primary spermatocytes, which included the pachytene to diplotene primary spermatocytes. (C) In the ovary, Dmc1 was localized in early oocytes, particularly at the leptotene to zygotene stage, whereas no specific staining was detected in the oogonia or in oocytes after the pachytene stage. (D) This antibody also immunostained the medaka Dmc1 protein in meiotic cells that were similar to those of tilapia. Scale bar, $10 \mu \mathrm{m}$.

Fig. 3 (Right). Germ cell differentiation in vitro organ culture. (A) Germ cell differentiation in vivo. Red region indicated the duration of in vitro organ culture of this study. (B,C) Immunohistochemical examination using the anti-Dmc1 antibody indicated that some of the germ cells were in meiosis. After 21 days of culture, the XY gonads contained a few germ cells but no meiotic cells (C), while the XX gonads contained numerous germ cells and meiotic cells (B). (D) Time schedule for the entry of germ cells into meiotic stage. When the gonads from XX fry at 23 dah were grown in the organ culture system, none of the germ cells in either sex had entered into meiosis at 7 days of culture, while only the XX gonads had entered into meiosis at 14 days of culture. (E,F) When XX fry were treated in vivo with $17 \alpha$-methyltestosterone (MT) from 12 to 20 dah, complete sex reversal (female to male) was induced (Table 1). The XX gonads generated by MT treatment of the XX fry at 23 dah were applied to the in vitro culture system. (E) Control XX gonads. (F) MT treated XX gonads. After culturing for 21 days, the XX gonads did not contain any germ cells that had entered into meiosis, in similarity to XY gonads (C). Scale bar, $10 \mu \mathrm{m}$.

in the spermatocytes but not in the spermatogonia, spermatids or spermatozoa. Further examination revealed that Dmc1 was localized in the early primary spermatocytes but not in the late primary spermatocytes, which included the pachytene to diplotene primary spermatocytes (Fig. 2B). In the ovary, Dmc1 was localized in early oocytes, particularly at the leptotene to zygotene stage, whereas no specific staining was detected in the oogonia or in oocytes after the pachytene stage (Fig. 2C). This specific staining pattern for Dmc1 was observed in the nuclei but not in the cytoplasm (Fig. 2B, C). This antibody also immunostained the medaka Dmc1 protein in meiotic cells, which were similar to those of tilapia (Fig. 2D). These findings indicate that Dmc1 expression occurs exclusively during the early meiotic stages in both sexes, and that Dmc1 protein represents an ideal molecular marker for
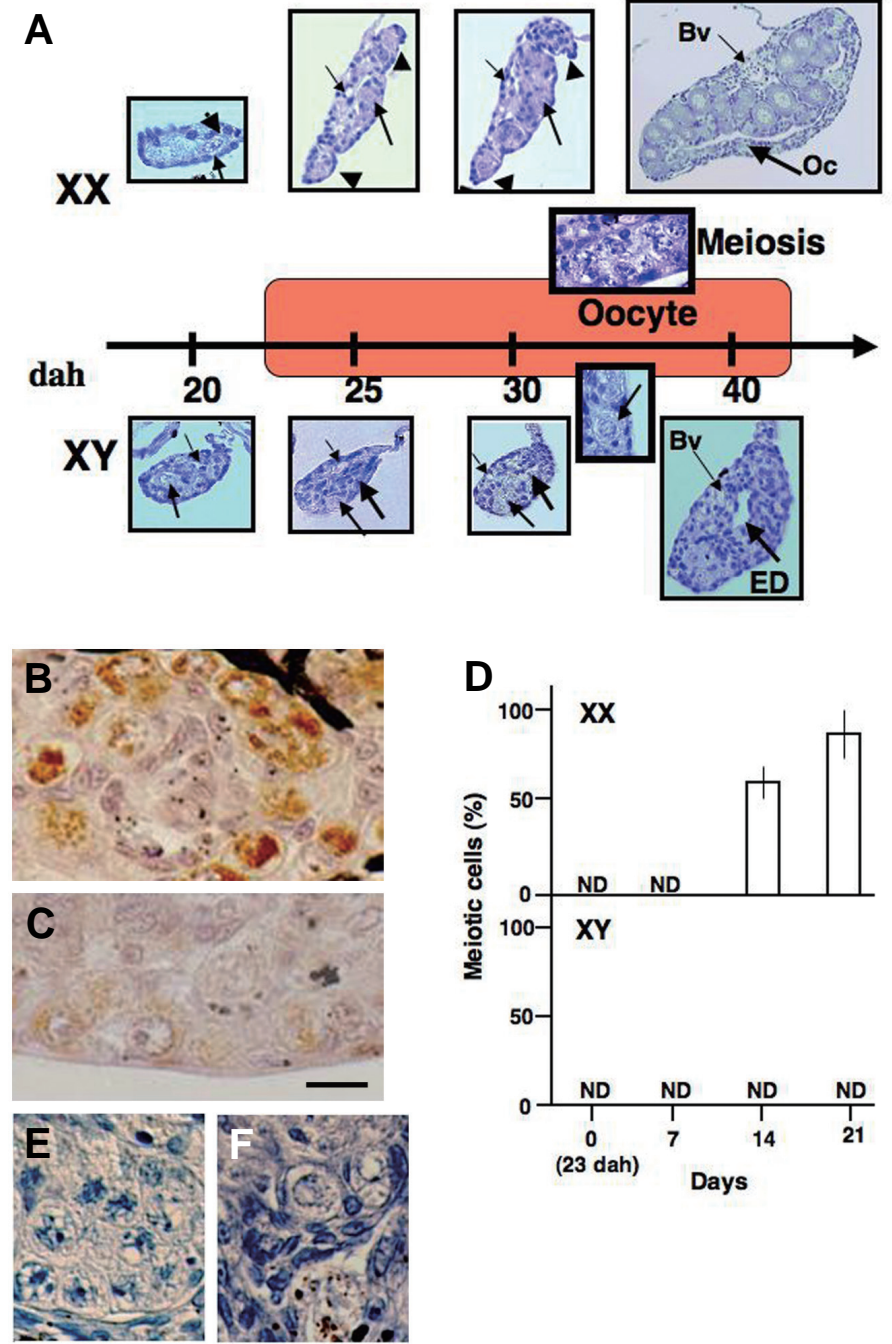

identifying the entry of germ cells into meiosis in teleost fish, including tilapia.

\section{In vitro germ cell differentiation}

When the gonads from $X X$ fry at 23 dah were grown in the organ culture system, none of the germ cells in either sex had entered into meiosis at 7 days of culture, while only the XX gonads had entered into meiosis at 14 days of culture (Fig. 3). Immunohistochemical examination using the anti-Dmc1 antibody demonstrated that some of the germ cells were in meiosis. After 21 days of culture, the $X Y$ gonads contained a few gonial germ cells but no meiotic cells (Fig. $3 \mathrm{C}, \mathrm{D}$ ), while the $\mathrm{XX}$ gonads contained numerous gonial germ cells and meiotic cells (Fig. 3 B,D). These results indicate that our in vitroculture system simulates the genetic sex- 


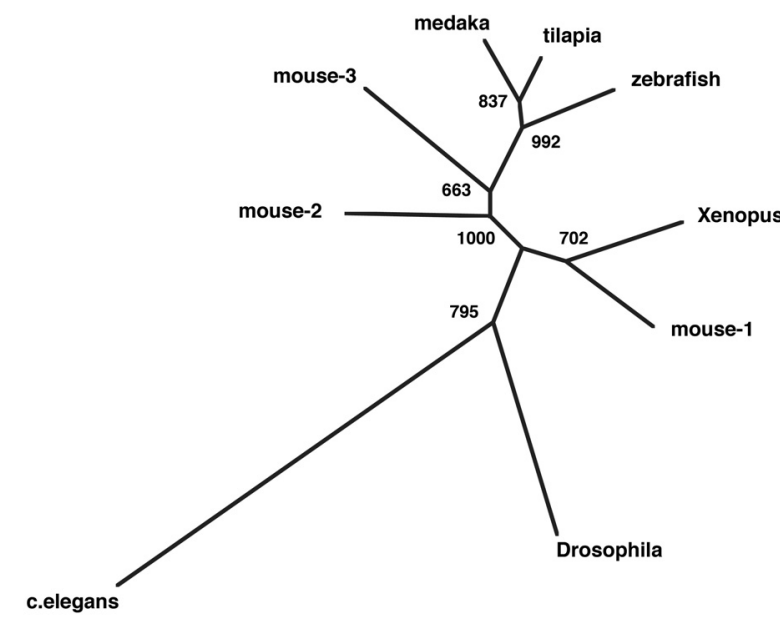

$\underline{0.1}$

Fig. 4 (Left). Phylogenetic tree of the amino acid sequences of nanos family. The tree was constructed with the neighbor-joining method. The numbers indicate bootstrap values from 1000 replicates. Horizontal lines indicate genetic distances. The GenBank accession numbers are: tilapia; AB453384, medaka; EU074259, zebrafish; NM131878, Xenopus; X72340, mouse (nos-1); NM178421, mouse (nos-2); NM194064, mouseu (nos-3); NM194059, Drosophila; M72421, C. elegans; NM063051.
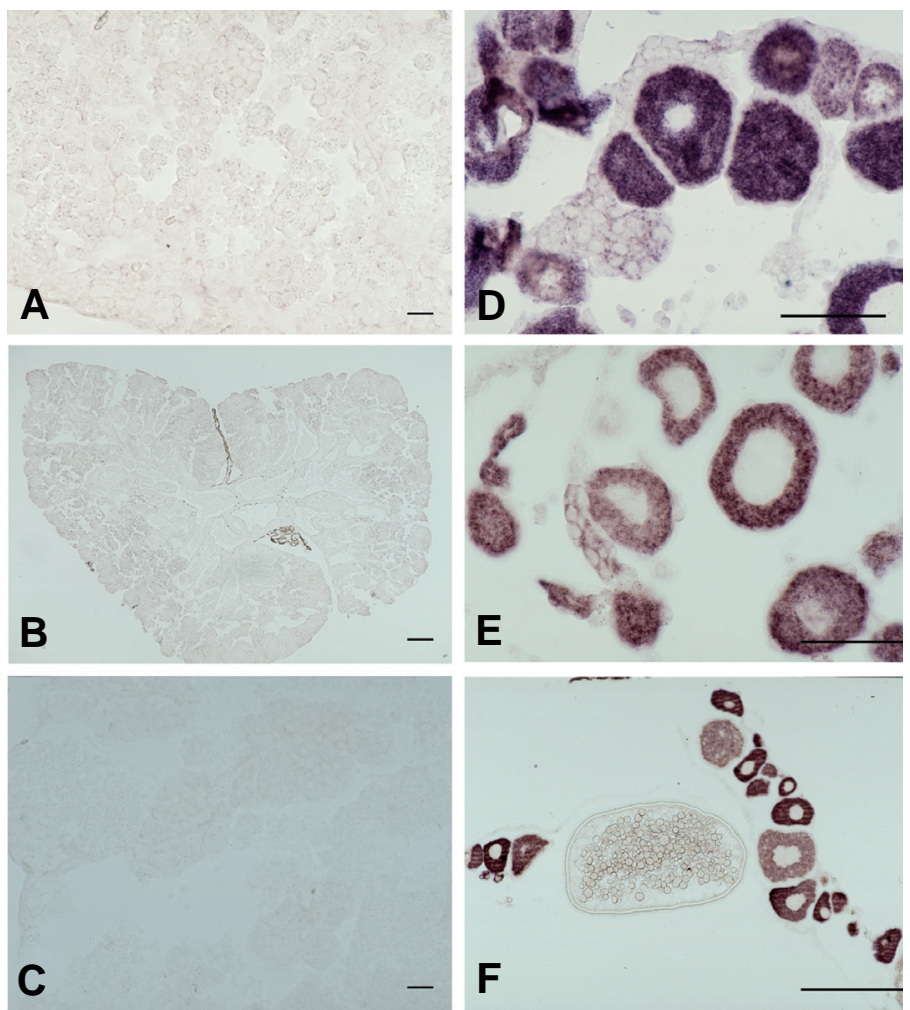

Fig. 5 (Right). Gene products involved in the entry of germ cells into meiosis. (A-C) Testis; (D,E) Ovary. (A,D) Tilapia. In situ hybridization analysis for FR-3 (tNos-1) indicated that tNos-1 was expressed in the germ cells of the XX gonads, particularly in the oogenic meiotic cells (D), but not in testicular cells. (B,E) Medaka. (C,F) Zebrafish. We also examined the expression profiles of nos-1 after gonadal formation in zebrafish and medaka. The zebrafish and medaka nos-1 genes were expressed in oogenic meiotic cells, specifically after gonadal formation, but not in testicular germ. Scale bar, 50 um.

dependent germ cell differentiation that occurs during gonadal sex differentiation in vivo. When $\mathrm{XX}$ fry were treated in vivo with $17 \alpha$-methyltestosterone (MT) from 12 to 20 dah, complete sex reversal (female to male) was induced (Table 1). Therefore, we applied the XX gonads generated by MT treatment of the XX fry at 23 dah to the in vitroculture system. After culturing for 21 days, the XX gonads did not contain any germ cells that had entered into meiosis (Fig. 3F), in similarity to $X Y$ gonads described above. This suggests that $X X$ gonads become differentiated as male gonads rather than as female gonads within 3 days after the induction of sex reversal by an androgen.

\section{Screening of gene products involved in the entry of germ cells into meiosis}

To identify gene products that are potentially involved in the entry of germ cells into meiosis or in the arrest of germ cells at the gonial stage of gonadal sex differentiation, we performed subtractive hybridization screening using the in vitroculture system. In all, 15 gene products were identified, 11 of which were expressed dominantly in XX gonads. One of the female-related genes, FR3 , was found to be similar to the zebrafish nanos-related gene 1 (nos) (Fig. 4). This gene was more similar to mouse nos-3 as compared to mouse nos-1 and nos-2. In situhybridization analysis showed that FR-3 was expressed in the germ cells of the XX gonads, particularly in the oogenic meiotic cells (Fig. 5B). RTPCR analysis for FR-3 indicated that FR-3 was expressed in the $\mathrm{XX}$ gonads around 35 dah, at which time-point the entry of germ cells into meiosis was observed. In contrast, FR-3 expression was not observed in the germ cells of the $X Y$ gonads (Fig. 6). To determine whether tilapia FR-3 is a nos homolog, we examined the expression profiles of nos after gonadal formation in zebrafish and medaka. The zebrafish and medaka nos genes were expressed in oogenic meiotic cells, specifically after gonadal formation (Fig. $5 \mathrm{C}-\mathrm{F}$ ), but not in testicular germ cells and oogonia. In addition, nos was expressed in migrated primordial germ cells, and its expression decreased with gonadal formation in tilapia (data not shown), as seen for zebrafish nos-1 and medaka nos (Koprunner et al., 2001; Kurokawa et al., 2006). These results indicate that the tilapia FR-3 is a nanos-related gene homolog

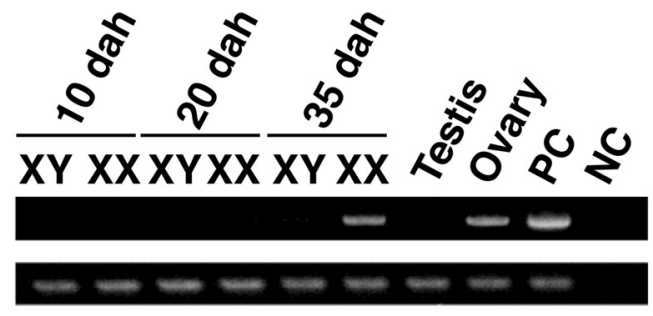

Fig. 6. RT-PCR analysis for $\boldsymbol{t}$ Nos-1 during gonadal differentiation in tilapia. RT-PCR analysis indicated that tNos-1 was expressed in the $X X$ gonads around 35 days after hatching, at which time-point the entry of germ cells into meiosis was observed (Kobayashi et al., 2002; 2008). In contrast, tNos-1 expression was not observed in the XY gonads. 
(nos), and suggest that nos is expressed in oogenic meiotic cells, especially after gonadal formation, in teleost fish.

\section{Discussion}

In this study, we developed an in vitro culture system for sex differentiation, which simulates the entry of germ cells into meiosis in $X X$ fry and the arrest of germ cells in the gonial stage in XY fry, in the teleost fish tilapia. Our experiments with this in vitroculture system demonstrate that germ cell differentiation (including meiosis) during gonadal sex differentiation progresses in a manner similar to that observed in vivo. To our knowledge, this is the first report that describes an in vitro culture system for studying the sexual dimorphism of germ cells during gonadal sex differentiation, with the exceptions of similar systems developed for the study of these phenomena in mammals.

Recent studies have elucidated some of the cellular and molecular events that occur during testicular somatic cell differentiation, such as testis cord formation (Tilmann and Capel, 2002). Nevertheless, many aspects of gonadal development, including the sex differentiation of embryonic germ cells, remain largely unclarified. In the mouse, sex differentiation of the somatic elements of the $X Y$ gonad is visually evident as the testis cord by $E 12.5$. It is not until E13.5 that the first meiotic germ cells appear in the $\mathrm{XX}$ gonads; in contrast, the $\mathrm{XY}$ germ cells cease mitotic proliferation and arrest as prospermatogonia (McLaren, 1984, 2000). In studies using chimeric gonads, it has been revealed that $X X$ embryonic germ cells in the testicular environment develop as male prospermatogonia, and that $X Y$ germ cells in the ovarian environment enter into meiosis, which suggests that the differentiation of germ cells as males or females is dependent upon the somatic environment rather than the sex chromosome content of the germ cell (mouse: McLaren and Monk, 1981; Taketo-Hosotani et al., 1989; Palmer and Burgoyne, 1991; medaka: Shinomiya et al., 2002). In the present study, when sex reversal of XX gonads was induced by androgen treatment from 12 to 20 dah, thereafter the XX germ cells never entered into meiosis during gonadal sex differentiation in vivo or in vitro, i.e., they resembled $X Y$ germ cells in this respect. In tilapia, sex differences in the histoarchitecture of the gonads are evident at 20 to 25 dah, particularly with respect to the ovarian cavity and the anlagen of the intratesticular efferent duct (Nakamura and Nagahama, 1985, 1989; Kobayashi et al., $2000,2008)$. A recent our report also indicated that androgeninduced testicular differentiation of $X X$ fry caused the induction of DMRT1 expression in medullary cells including germ cell-surrounding cells (Kobayashi et al., 2008). These results suggest that the development of teleost germ cells during gonadal sex differentiation is dependent upon the somatic milieu, as in the mouse.

In the present study, we attempted to screen for gene products involved in meiosis during gonadal sex differentiation using our established in vitro culture system. One of the identified gene products, FR-3, was expressed in oogenic meiotic cells, particularly after gonadal formation. InterestinglyॅFR-3 is similar to the zebrafish nanos-related gene 1 (nos). It remains unclear as to whether the nanos homolog is expressed in oogenic cells after gonadal formation in non-mammalian vertebrates. For the mouse, three types of nanos homolog have been reported (Haraguchi et al., 2003; Tsuda et al., 2003), each of which has a specific expression profile and function, i.e., nanos- 1 is expressed pre- dominantly in the central nervous system, and nanos-2 and nanos3 are expressed in germ cells in a cell-specific fashion. In particular, nanos-2 and nanos-3 are expressed in male PGCs and migrating PGCs, respectively. In fish, nos is expressed in migrating PGCs (Koprunner et al., 2001; Kurokawa et al., 2006). This suggests that the expression profile of nos in teleost fish after gonadal formation is similar to that in the mouse, and that the expression during PGC migration is similar to that of nanos-3 in the mouse. However, in contrast to nanos- 2 and nanos-3 in the mouse, the fish nos is not expressed in germ cells after the PGC reach the gonadal anlagen in both sexes, and it is re-expressed in oogenic meiotic cells but not in oogonia or $X Y$ germ cells. This suggests that fish nos plays a role in oogenesis that is distinct from that of the homolog in the mouse. Although the role of nos in oogenesis has not been elucidated, to date, a recent study suggests that nos plays a role for maintain of oocytes in zebrafish (Draper et al., 2007). Together with the expression profiles of nos in teleosts, the role of nos for oogenesis may be conserved in teleost fish including zebrafish, tilapia and medaka. Further studies are necessary for clarification of the function of nos during oogenesis in teleost fish.

In the present study, we established an in vitro culture system for germ cell differentiation during gonadal sex differentiation, including the meiotic transition in females and the arrest of germ cells in the gonial stage. Recent reports have suggested that the retinoic acid pathway and pstgD2/PGC-7 play important roles in meiotic transition during gonadal sex differentiation in the mouse (Adams and McLaren, 2002; Bowles et al., 2006; Koubova et al., 2006). However, it remains unclear whether these molecules are conserved in vertebrates. Recent findings suggested that $17 \alpha, 20 \beta$ dihydroxy-4-pregnen-3-one (17,20 $\beta$-DP) is involved in initiating meiosis in the teleost fishes, male eel and female Japanese huchen as well as common carp (Miura et al., 2006; 2007). In addition, a recent report in tilapia showed that teleost specific Cyp17 isoform, Cyp17a2, lacking lyase activity synthesized 17,20 3 DP efficiently and exhibited sexual dimorphic expression during gonadal differentiation by starting the expression at 11 and 75 dah in XX and XY gonads, respectively (Zhou etal., 2007). In tilapia, the initiation of meiosis occurred around 35 and 85 dah (Kobayashi et al., 2000; 2008). Although a time lag exists between Cyp17a2and the initiation of meiosis, 17,20ß-DP might be involved in initiating meiosis during gonadal differentiation. Further study will be necessary to demonstrate this hypothesis. To address these questions, further analyses using the novel in vitroculture system established in this study will be available as a powerful tool.

\section{Materials and Methods}

\section{Animals}

Nile tilapia were kept in re-circulating fresh-water tanks with a capacity of $500 \mathrm{~L}$ at $26 \pm 1^{\circ} \mathrm{C}$ until use. As described in our previous report (Kobayashi et al., 2000), all the genetic females (XX) and males (XY) were obtained by artificial fertilization of eggs from a normal female $(X X)$ with sperm from a sex-reversed male $(X X)$ or from a supermale $(Y Y)$, respectively. Fertilized eggs were cultured in re-circulating water at $26 \pm 1^{\circ} \mathrm{C}$. In our system, no hermaphroditic gonads were observed, as described previously (Kobayashi et al., 2000, 2002, 2003).

\section{Induction of sex reversal}

The XX fry were fed commercial food (OTOHIME, Marubeni-Nisshin Feed Co. Ltd., Japan) containing $10 \mu \mathrm{g} 17 \alpha$-methyltestosterone (MT; 
Sigma Co. Ltd., St. Louis) per gram of diet 12 to 20 days after hatching (dah). This food was given four times a day. The food was immersed in ethanol or ethanol containing MT for the control and the MT treatment, respectively. Then, the food was dried at $37^{\circ} \mathrm{C}$ overnight. MT containing food caused complete sex reversal to functional males (12 to 20 dah: $45 /$ 45 males and 0/45 females, see Table 1).

\section{Production of the anti-Dmc1 antibody}

To generate antibodies against Dmc1, we used as the immunizing antigen an oligopeptide that corresponds to the C-terminal amino acid sequence (tilapia Dmc1: AB18246, Kajiura-Kobayashi et al., 2005) predicted from tilapia Dmc1 cDNA, with the addition of a cysteine at the $\mathrm{N}$ terminus to facilitate linkage to the carrier protein, as described previously (Kobayashi et al., 1996). Conjugation of the antigen to bovine serum albumin (BSA, fraction V; Sigma Chemical Co., St. Louis, MO) as the carrier protein was performed as described previously (Kobayashi et al., $1998,2002)$. Female Guinea pigs were immunized at 2-week intervals with four subcutaneous injections of peptide-linked protein $(0.5 \mathrm{mg} /$ Guinea pig/injection). Each antigen was emulsified in Freund's complete adjuvant for the first injection and in Freund's incomplete adjuvant for subsequent injections. One week after the last injection, blood samples were collected. Serum was separated and purified by affinity chromatography using the appropriate synthetic peptide. The specificity of the purified Dmc1 antibody was determined by assaying for reactivity with recombinant tilapia Dmc1 and Rad51 (Rad51: AB182647; KajiuraKobayashi et al., 2005), which is a Rec A homolog and not a meiosisspecific gene product, generated using the rabbit reticulocyte lysate system (Promega, Madison, WI). In addition, proteins extracted from the ovary and testis were immunoblotted with the antibody, as described previously (Kobayashi et al., 1996, 1998a,b). Anti-Dmc1 and anti-His antibodies were used at 1:1000 and 1:500 dilutions, respectively.

\section{In vitro organ culture}

The $X X$ and $X Y$ gonads from fry 23 days after hatching (dah) were applied to an in vitro organ culture system, which comprised L-15 medium $/ 10 \mathrm{mM}$ Hepes ( $\mathrm{pH} 7.4$ ) that contained $0.5 \%$ BSA (fraction V), at $26^{\circ} \mathrm{C}$. Briefly, gonads were placed onto the floats of $1.5 \%$ agarose block covered with a nitrocellulose membrane in 24-well plastic tissue culture dishes. The culture medium was exchanged once a week. After culture, the gonads were fixed in Bouin's fixative solution and embedded in paraffin. The gonads (5- $\mu \mathrm{m}$-thick sections) were immunostained with 1:1000 dilutions of the anti-Vasa (Kobayashi et al., 2002) and anti-Dmc1 antibodies. The sections were then stained with Carazzi's hematoxylin. Immunohistochemistry methods used have been described previously (Morrey et al., 1998; Kobayashi et al., 1998a, b; 2002).

\section{Subtractive hybridization screening using the in vitro culture sys- tem}

Subtractive hybridization screening was performed as described previously (Kobayashi etal., 2003), using total RNA samples derived from XX and $X Y$ gonads that were cultured for 14 days (corresponding to 37 dah gonads) in the organ culture system described in the present study.

\section{Acknowledgements}

We thank to Professor $Y$. Nagahama in NIBB for his courtesy throughout this work and Dr. H. Kajiura-Kobayashi in NIBB for her technical advice. This work was supported in part by a Grant-in-Aid for Research for Priority Area from the Ministry of Education, Science, Sports and Culture of Japan.

\section{References}

ADAMS IR and MCLAREN A. (2002). Sexually dimorphic development of mouse primordial germ cells: switching from oogenesis to spermatogenesis. Develop ment. 129: 1155-1164.
BOWLES J, KNIGHT D, SMITH C, RICHMAN J, MAMIYA S, YASHIRO K CHAWENGSAKSOPHAK $\mathrm{K}$, WILSON MJ, ROSSANT J, HAMADA H abd KOOPMAN P. (2006). Retinoid signaling determines germ cell fate in mice. Science. 312: 596-600.

DRAPER BW, MCCALLUM CM and MOENS CB. (2007). nanos1 is required to maintain oocyte production in adult zebrafish. Dev. Biol. 305: 589-598.

HARAGUCHIS, TSUDA M, KITAJIMA S, NOMURA-KITABAYASHI A, KUROKAWA $K$ and SAGA Y. (2003). nanos1: a mouse nanos gene expressed in the central nervous system is dispensable for normal development. Mech. Dev.120: 721 731.

HARDISTY MW. (1967). The numbers of vertebrate primordial germ cells. Biol. Rev. Camb. Philos. Soc. 42: 265-287.

KAJIURA-KOBAYASHI H, KOBAYASHI T and NAGAHAMA Y. (2005). Cloning of cDNAs and the differential expression of A-type cyclins and Dmc1 during spermatogenesis in the Japanese eel, a teleost fish. Dev. Dyn. 232: 1115-1123.

KOBAYASHI T, CHANG XT, KAJIURA $H$, NAKAMURA $M$ and NAGAHAMA $Y$. (1996). Fish 3b-hydroxysteroid dehydrogenase 5-4isomerase: Antibody production and their use for the immunohistochemical detection of fish steroidogenic tissues. Zool. Sci. 13: 909-914.

KOBAYASHI T, NAKAMURA M, KAJIURA-KOBAYASHI H, YOUNG G. and NAGAHAMA Y. (1998a). Immunolocalization of steroidogenic enzymes (P450scc, P450c17, P450arom and 3beta-HSD) in immature and mature testes of rainbow trout (Oncorhynchus mykiss). Cell Tissue Res. 292: 573-577.

KOBAYASHI T, KAJIURA-KOBAYASHI H. and NAGAHAMA Y. (1998b). A novel stage-specific antigen is expressed only in early stages of spermatogonia in Japanese eel, Anguilla japonica testis. Mol. Reprod. Dev. 51: 355-361.

KOBAYASHI T, KAJIURA-KOBAYASHI H and NAGAHAMA Y. (2000). Differential expression of vasa homologue gene in the germ cells during oogenesis and spermatogenesis in a teleost fish, tilapia, Oreochromis niloticus. Mech. De velop. 99: 139-142.

KOBAYASHIT, KAJIURA-KOBAYASHI H and NAGAHAMAY. (2002). Two isoforms of vasahomologs in a teleost fish: their differential expression during germ cell differentiation. Mech. Develop. 111: 167-171

KOBAYASHI T, KAJIURA-KOBAYASHI H and NAGAHAMA Y. (2003). Induction of $X Y$ sex reversal by estrogen involves altered gene expression in a teleost, tilapia. Cytogenet. Genome Res. 101: 289-294.

KOBAYASHI T, KAJIURA-KOBAYASHI H, GUAN G and NAGAHAMA Y. (2008) Sexual dimorphic expression of DMRT1 and Sox9a during gonadal differentiation and hormone-induced sex reversal in the teleost fish Nile tilapia (Oreochromis niloticus). Dev. Dyn. 237: 297-306.

KOPRUNNER M, THISSE C, THISSE B and RAZ E. (2001). A zebrafish nanosrelated gene is essential for the development of primordial germ cells. Genes Dev. 15: 2877-85.

KOUBOVA J, MENKE DB, ZHOU Q, CAPEL B, GRISWOLD MD and PAGE DC (2006). Retinoic acid regulates sex-specific timing of meiotic initiation in mice. Proc. Natl. Acad. Sci. USA. 103: 2474-2479.

KUROKOWA H, AOKI Y, NAKAMURA S, EBE Y, KOBAYASHI D and TANAKA M (2006). Time-lapse analysis reveals different modes of primordial germ cell migration in the medaka Oryzias latipes. Dev. Growth Differ. 48: 209-221.

MATSUDA M, NAGAHAMA Y, SHINOMIYA A, SATO T, MATSUDA C, KOBAYASHI T, MORREY CE, SHIBATA N, ASAKAWA S, SHIMIZU N, HORI H, HAMAGUCHI S and SAKAIZUMI M. (2002). DMY is a Y-specific DM-domain gene required for male development in the medaka fish. Nature. 417: 559-563.

MATSUDA M, SATO T, TOYOZAKI Y, NAGAHAMA Y, HAMAGUCHI $S$ and SAKAIZUMI M. (2003). Oryzias curvinotus has DMY, a gene that is required for male development in the medaka, O. latipes. Zool. Sci. 20: 159-161.

MCLAREN A. (1984). Mammalian development: methods and success of nuclear transplantation in mammals. Nature. 309: 671-672.

MCLAREN A. (2000). Germ and somatic cell lineages in the developing gonad. Mol. Cell. Endocrinol. 163: 3-9

MCLAREN A. (2003). Primordial germ cells in the mouse. Dev. Biol. 262: 1-15.

MCLAREN A and MONK M. (1981). X-chromosome activity in the germ cells of sexreversed mouse embryos. J. Reprod. Fertil. 63: 533-537.

MCLAREN A and SOUTHEE D. (1997). Entry of mouse embryonic germ cells into meiosis. Dev. Biol. 187:107-113. 
MIURA T, HIGUCHI M, OZAKI Y, OHTA T and MIURA C. (2006) Progestin is an essential factor for the initiation of the meiosis in spermatogenetic cells of the eel. Proc. Natl. Acad. Sci. USA. 103:7333-7338.

MIURA C, HIGASHINO T and NIURA T. (2007) A progestin and an estrogen regulate early stages of oogenesis in fish. Biol. Reprod. 77:822-828.

MORREY C, NAKAMURA M, KOBAYASHI T, GRAU EG and NAGAHAMA Y. (1998) P450scc-like immunoreactivity throught gonadal restructuring in the protogynous hermaphrodite Thalassoma duperrey. Int. J. Dev. Biol. 42: 811 816.

NAKAMURA M and NAGAHAMA Y. (1985). Steroid producing cells during ovarian differentiation of the tilapia, Salotherodon niloticus. Dev. Growth Differ. 27: 701708.

NAKAMURA M and NAGAHAMA Y. (1989). Differentiation of Leydig cells and, and changes of testosterone levels during testicular differentiation in tilapia, Oreochromis niloticus, Fish Physiol. Biochem. 7: 211-219.

NAKAMURA M, KOBAYASHI T, CHANG XT and NAGAHAMA Y. (1998). Gonadal sex differentiation in teleost fish. J. EXp. Zool. 281: 362-372.

NANDA I, KONDO M, HORNUNG U, ASAKAWA S, WINKLER C, SHIMIZU A SHAN Z, HAAF T, SHIMIZU N, SHIMA A, SCHMID M and SCHARTL M. (2002). A duplicated copy of DMRT1 in the sex-determining region of the $Y$ chromosome of the medaka, Oryzias latipes. Proc. Natl. Acad. Sci. USA. 99: 11778-11783.

PALMER SJ and BURGOYNE PS. (1991). In situanalysis of fetal, prepuberal and adult $X X----X Y$ chimaeric mouse testes: Sertoli cells are predominantly, but not exclusively, XY. Development. 112: 265-268.

PITTMA DL, COBB J, SCHIMENTI KJ, WILSON LA, COOPER DM, BRIGNULL E, HANDEL MA and SCHIMENTI JC. (1998). Meiotic prophase arrest with failure of chromosome synapsis in mice deficient for Dmc1, a germline-specific RecA homolog. Mol Cell. 1: 697-705
SCHWACHA A and KLECKNER N. (1997). Interhomolog bias during meiotic recombination: meiotic functions promote a highly differentiated interhomologonly pathway. Cell. 90: 1123-1135.

SHINOMIYA A, SHIBATA N, SAKAIZUMI M and HAMAGUCHI S. (2002) Sex reversal of genetic females $(X X)$ induced by the transplantation of $X Y$ somatic cells in the medaka, Oryzias latipes. Int. J. Dev. Biol. 46: 711-717.

TAKETO-HOSOTANI T, NISHIOKA Y, NAGAMINE CM and MERCHANT-LARIOS H. (1989). Development and fertility of ovaries in the B6.YDOM sex-reversed female mouse. Development. 107: 95-105.

TARSOUNAS M, MORITA T, PEARLMAN RE and MOENS PB. (1999). RAD51 and DMC1 form mixed complexes associated with mouse meiotic chromosome cores and synaptonemal complexes. J. Cell Biol. 147: 207-220.

TILMANN C and CAPEL B. (2002). Cellular and molecular pathways regulating mammalian sex determination. Recent Prog. Horm. Res. 57: 1-18.

TSUDA M, SASAOKA Y, KISO M, ABE K, HARAGUCHI S, KOBAYASHI S and SAGA Y. (2003). Conserved role of nanos proteins in germ cell development. Science. 301: 1239-1241.

WOLGEMUTH DJ. (2003). Insights into regulation of the mammalian cell cycle from studies on spermatogenesis using genetic approaches in animal models. Cytogenet. Genome Res. 103: 256-266.

YOSHIDA K, KONDOH G, MATSUDA Y, HABU T, NISHIMUNE $Y$ and MORITA T. (1998). The mouse RecA-like gene Dmc1 is required for homologous chromosome synapsis during meiosis. Mol. Cell. 1: 707-718.

ZHOU LY, WANG DS, KOBAYASHI T, YANO A, PAUL-PRASANTH B, SUZUKI A SAKAI F and NAGAHAMA Y. (2007). A novel type of P450c17 lacking the lyase activity is responsible for C21-steroid biosynthesis in the fish ovary and head kidney. Endocrinology. 148: 428-491. 
Further Related Reading, published previously in the Int. J. Dev. Biol.

See our Special Issue Pattern Formation edited by Cheng-Ming Chuong and Michael K. Richardson at: http://www.ijdb.ehu.es/web/contents.php?vol=53\&issue=5-6

Visualization of primordial germ cells in vivo using GFP-nos1 3'UTR mRNA

Taiju Saito, Takafumi Fujimoto, Shingo Maegawa, Kunio Inoue, Minoru Tanaka, Katsutoshi Arai and Etsuro Yamaha Int. J. Dev. Biol. (2006) 50: 691-700

The formation of primordial germ cells from germline cells in spherical embryos derived from the blastodisc of 2-cell embryos in goldfish, Carassius auratus

Satoshi Otani, Tomoe Kitauchi, Taiju Saito, Suzu Sakao, Shingo Maegawa, Kunio Inoue, Katsutoshi Arai and Etsuro Yamaha Int. J. Dev. Biol. (2005) 49: 843-850

\section{Primordial germ cell migration}

Kathleen Molyneaux and Christopher Wylie

Int. J. Dev. Biol. (2004) 48: 537-543

mgm 1, the earliest sex-specific germline marker in Drosophila, reflects expression of the gene esg in male stem cells.

Adrian Streit, Luca Bernasconi, Pavel Sergeev, Alex Cruz and Monica Steinmann-Zwicky Int. J. Dev. Biol. (2002) 46: 159-166

Germ cells, gonads and sex reversal in marsupials.

$M$ B Renfree and G Shaw

Int. J. Dev. Biol. (2001) 45: 557-567

The allocation and differentiation of mouse primordial germ cells.

T E Tsang, P L Khoo, R V Jamieson, S X Zhou, S L Ang, R Behringer and P P Tam Int. J. Dev. Biol. (2001) 45: 549-555

Differentiation of mouse primordial germ cells into female or male germ cells.

N Nakatsuji and S Chuma

Int. J. Dev. Biol. (2001) 45: 541-548

Germ cell biology-from generation to generation.

P J Donovan, M P De Miguel, M P Hirano, M S Parsons and A J Lincoln

Int. J. Dev. Biol. (2001) 45: 523-531

Twenty years of research on primordial germ cells.

M De Felici

Int. J. Dev. Biol. (2001) 45: 519-522



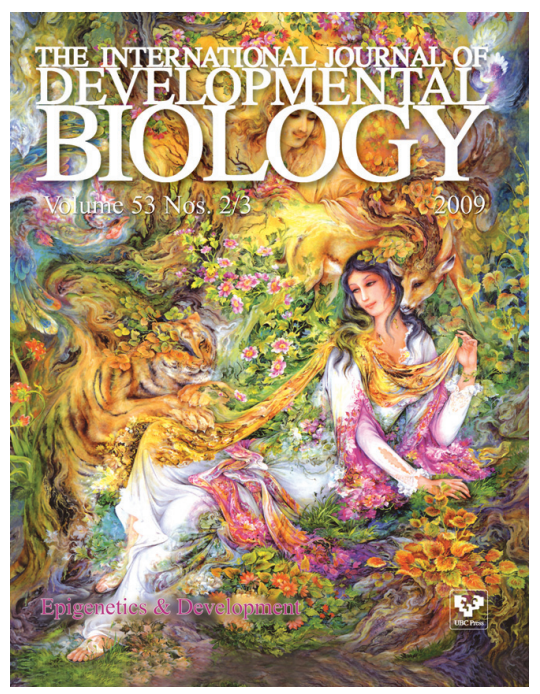

5 yr ISI Impact Factor $(2008)=3.271$



